\title{
Nilai Pendidikan Karakter Pada Film Sang Kiai
}

\author{
Wegig Widiyatmaka ${ }^{1}$, Edy Tri Sulistyo ${ }^{2}$, Sugeng Nugroho ${ }^{3}$ \\ 1,2,3 Magister of Art Education, Teacher Training and Education, Sebelas Maret University \\ wwidiyatmaka@gmail.com
}

Tujuan dari penelitian ini adalah untuk menganalisis pendidikan karakter dalam film Sang Kiai sebagai pembangunan karakter untuk media pembelajaran yang relevan. Sumber data diperoleh dengan mengamati cerita dari film Sang Kiai secara langsung. Teknik untuk mengumpulkan data menggunakan ulasan dokumen atau mendengarkan dan mempelajari literatur. Analisis data menggunakan teori sinematografi dengan mengamati adegan dan dialog dalam film Kiai. Hasil penelitian menunjukkan bahwa ada nilai-nilai pendidikan karakter yang disampaikan melalui adegan dalam film. Nilai-nilai pendidikan karakter dalam film Sang Kiai dapat dipahami dari dialog dan adegan yang dimainkan oleh para pemain. Film Sang Kiai berisi 8 nilai pendidikan karakter yang terkandung dalam film ini termasuk agama, disiplin, kerja keras, demokratis, rasa ingin tahu, semangat nasional, penghargaan terhadap prestasi, persahabatan / komunikatif yang tercermin dalam setiap adegan dalam film "The Kiai". Film Kiai berisi nilai-nilai pendidikan karakter yang relevan sebagai pembangunan karakter. Film ini dapat digunakan sebagai media pembelajaran yang bertujuan pembentukan karakter.

Kata kunci: nilai pendidikan karakter, pembentukan karakter film

\section{Values Of Character Education In The Sang Kiai Film}

The purpose of this study is to analyze character education in the film Sang Kiai as character building for relevant learning media. Data sources are obtained by observing stories from the film Sang Kiai directly. Techniques for collecting data using document review or listening and study literature. Data analysis uses cinematographic theory by observing scenes and dialogues in the movie Kiai. The results of the study show that there are values of character education delivered through the scenes in the film. The values of character education in the film Sang Kiai can be understood from the dialogue and scenes played by the players. The Sang Kiai film contains 8 values of character education contained in the film including religious, disciplined, hard work, democratic, curiosity, national spirit, respect for achievement, friendship / communicative which is reflected in every scene in the film "The Kiai". The Kiai's film contains relevant character education values as character building. The film can be used as a learning media that aims at character formation.

Key Words : the value of character education, film character formation

Proses Review : 7 - 25 Januari 2019, Dinyatakan Lolos: 29 Januari 2019 


\section{PENDAHULUAN}

Film merupakan salah satu media komunikasi modern yang efektif untuk menghibur sekaligus menyampaikan pesan yang dapat mempengaruhi sikap, pola pikir dan membuka wawasan bagi para penonton. Kita dapat melihat imajinasi sutradara yang dituangkan secara apik dalam sebuah film. Pada setiap pembuatan film, film-maker memiliki cara tersendiri untuk menyampaikan pesan kepada khalayak dengan audio dan visualnya.

Menurut Pratista (2008:1) film secara umum dapat dibagi atas dua unsur pembentuk diantaranya unsur naratif dan unsur sinematik. Dua unsur tersebut saling berinteraksi dan berkesinambungan satu sama lain untuk membentuk sebuah film. Jika hanya salah satu yang berdiri tidak dapat sebuah film terbentuk. Dapat dikatakan bahwa unsur naratif adalah bahan (materi) yang akan diolah, sementara unsur sinematik adalah cara (gaya) untuk mengolahnya.

Menurut Pratista (2008:1) unsur naratif merupakan unsur yang berhubungan dengan aspek cerita atau tema film. Cerita film pasti memiliki unsur-unsur seperti tokoh, masalah, konflik, lokasi, waktu serta lainnya. Seluruh elemen tersebut membentuk unsur naratif secara keseluruhan sementara unsur sinematik atau juga sering diistilahkan gaya sinematik merupakan aspek-aspek teknis pembentuk film. Unsur sinematik terbagi menjadi empat elemen pokok yakni, mise-en-scene, sinematografi, editing, dan suara. Unsur naratif berhubungan dengan aspek cerita atau film. Unsur naratif adalah suatu rangkaian peristiwa yang berhubungan satu sama lain dan terikat oleh logika sebab-akibat (kausalitas) yang terjadi dalam suatu ruang dan waktu.

Film "Sang Kiai" merupakan film yang diproduksi oleh Rapi Film yang disutradarai oleh Rako Prijanto. Rapi Film kembali berkreasi untuk film terbarunya yang akan mengangkat kisah dari seorang tokoh perjuangan atau tokoh perjuangan pesantren Tebu Ireng, Jombang Nahdlatul Ulama (NU) yaitu beliau KH. Hasyim Asy'ari kakek dari beliau Haji Abdurrahman Wahid atau yang lebih dikenal dengan Gus Dur.

Film "Sang Kiai" merupakan film yang mengisahkan Kyai Haji Hasyim Asyari tokoh yang sangat baik menjadi panutan banyak orang. Hasyim Asyari menjadi seorang kyai yang banyak memberikan dakwah dan mendidik santri-santrinya menjadi orang yang beriman dan memiliki karakter yang kuat. Di era sekarang sangat diperlukan pendidikan karakter sebab berbagai peristiwa negatif sering terjadi dan dapat kita jumpai di media mau pun di sekitar kita. Contoh peristiwa negatif yang terjadi diantaranya dari pem- bunuhan, penipuan, pemerkosaan, korupsi dan masih banyak lagi. Untuk mengatasinya maka bangsa ini memerlukan pendidikan karakter kuat dan panutan yang baik.

Berdasarkan fenomena tersebut mengundang ketertarikan untuk meneliti dan mengkaji film "Sang Kiai" dengan sudut pandang dari segi pendidikan karakter. Selain itu memberikan refrensi film terhadap khalayak sebagai tontonan dan tuntunan yang baik kepada masyarakat.

\section{Perumusan Masalah}

Berdasarkan uraian latar belakang di atas rumusan masalah penelitian ini adalah:

1. Apakah film Sang Kiai dapat memberikan nilai pendidikan karakter?

2. Bagaimana nilai-nilai pendidikan karakter dalam film "Sang Kiai"?

3. Mengapa film "Sang Kiai" memiliki pesan pendidikan sebagai pembentukan karakter?

\section{Tujuan Penelitian}

Penelitian ini bertujuan:

1. Mendeskripsikan dan menjelaskan film Sang Kiai dapat memberikan nilai pendidikan karakter

2. Mendeskripsikan dan menjelaskan nilai pendidikan karakter dalam film "Sang Kiai"

3. Menganalisis pesan pendidikan terutama pembentukan karakter yang terdapat pada film "Sang Kiai”

\section{Manfaat Penelitian \\ Manfaat Teoritis}

Harapan dari penelitian ini mampu menambah wawasan pembaca serta dapat memberikan refrensi teori penelitian pada film, khususnya teori-teori yang kaitanya dengan psikologi pendidikan yang menyangkut mengenai nilai-nilai pendidikan karakter.

\section{Manfaat Praktis}

Bagi para pendidik seni, khususnya guru seni budaya, guru multimedia, guru broadcasting, setelah membaca penelitian ini diharapkan tidak hanya mengajar praktek semata, namun juga dapat memberikan contoh nilai-nilai pendidikan karakter kepada peserta didik melalui sebuah film atau media di saat proses kegiatan belajar mengajar.

Bagi para pembuat film, khususnya untuk memberikan apresiasi bagi pembuat film "Sang Kiai" yang telah menghasilkan karya film terbaik di ajang Festival Film Indonesia pada tahun 2013. Serta memberikan informasi melalui hasil analisis film "Sang Kiai" yang sangat relevan dengan nilai-nilai pendidikan karakter. 


\section{Bagi masyarakat.}

Mengembangkan pendidikan karakter melalui nilainilai pendidikan karakter agar menjadi jati diri bangsa yang kuat.

Dapat memberikan referensi dalam memperluas khazanah tentang pendidikan seni khususnya seni media rekam.

Memberikan refrensi film yang mendidik dan bermutu untuk ditonton semua khalayak.

Bagi lembaga pendidikan nasional, dapat memberikan masukan kepada lembaga pendidikan nasional khususnya untuk mengembangkan pendidikan karakter melalui pendidikan seni. Sebagai penerus bangsa pendidikan karakter penting ditanamkan pada peserta didik agar tumbuh menjadi generasi yang mampu mengembangkan potensi dirinya. Pendidikan karakter dapat ditanamkan salah satunya melalui seni media rekam.

\section{Kerangka Dasar Teori \\ Film}

Pengertian film (sinema) secara harfian adalah Cinemathographie yang berasal dari cinema dan tho atau phytos yang berarti cahaya serta graphie atau graph yang berarti gambar. Jadi pengertiannya adalah melukis gerak dengan cahaya. Gambar bergerak (fillm) adalah bentuk dominan dari komunikasi massa visual dibelahan dunia ini (Elvinaro, 2004:143). Sejalan dengan perkembangan media penyimpanan dalam bidang sinematografi, maka pengertian film telah bergeser. Sebuah film cerita dapat diproduksi tanpa menggunakan seluloid (media film).Bahkan saat ini sudah semakin sedikit film yang menggunakan media seluloid pada tahap pengambilan gambar. Ada tahap paska produksi gambar yang telah diedit dari media analog maupun digital dapat disimpan ada media yang fleksibel. Hasil akhir karya sinematografi dapat disimpan pada media seluloid, analog maupun digital. Secara umum, film dapat dibagi dua unsur pembentukan, yakni unsur naratif dan unsur sinematik. Keduanya saling berinteraksi dan berkesinambungan satu sama lain untuk membentuk sebuah film. Unsur naratif adalah bahan (materi) yang akan diolah, sementara unsur sinematik adalah cara (gaya) untuk mengolahnya. Dalam film cerita, unsur naratif adalah perlakuan terhadap cerita film, sedangkan unsur sinematik merupakan aspek-aspek teknis pembentukan film.

Film sebagai media pendidikan karakter. Film banyak berperan dalam Film atau salah satu bentuk hiburan yang populer, yang menjadikan manusia melarutkan diri dalam dunia imajinasi untuk waktu tertentu. Film berfungsi informative maupun edukatif bahkan persuasife. Pengertian di atas dapat di tarik kesimpulan bahwa Film merupakan merupakan serangkaian gambar yang diambil dari obyek bergerak, yang kemudian menghasilkan serial peristiwa-peristiwa secara kontinyu dan berfungsi sebagai media komunikasi, media hiburan, pendidikan dan penerangan serta diiringi dengan unsur ekspresi penguat seperti musik, dialog dan juga warna sehingga mampu membuat film itu menjadi serealistis mungkin sehingga memperoleh nilai estetika yang sempurna. Kehidupan sehari-hari, film ikut mempengaruhi prilaku para penontonnya hal tersebut dapat terlihat dari banyak orang yang mengikuti cara berpakaian, cara berbicara, bahkan gaya hidup sehari-hari.

Film merupakan media yang menembus seluruh lapisan masyarakat, oleh karena itu film harus dapat memenuhi salah satu fungsi film agar dapat memberi inspirasi atau perubahan bagi para penontonnya.dalam penelitian ini lebih menekankan pada film setiap individu yang telah mengalami dan mengenal pendidikan mampu meng-hormati atau menghargai orang tua.

\section{METODE PENELITIAN}

\section{Jenis Penelitian}

Jenis penelitian yang dilakukan dalam penyusunan penelitian ini adalah jenis penelitian deskriptif kualitatif. Menurut Kriyantono (2006:69) penelitian deskriptif berupaya mengambarkan atau menguraikan hal dengan apa adanya serta menggunakan data kualitatif yang akan menghasilkan data deskriptif berupa kata-kata tertulis atau lisan dari orang dan perilaku yang dapat diamati.

Setelah itu dideskriptifkan dan dianalisis secara utuh untuk menemukan hasil penulisan. Objek penulisan adalah dialog dan adegan dalam film "Sang Kiai" yang menampilkan nilai pendidikan karakter sebagai pembentukan karakter.

\section{Fokus penelitian}

\section{Unsur Sinematik}

Mengenai keberadaan film "Sang Kiai", memberikan banyak kesan dan bisa menyampaikan isi pesan film tersebut. Dalam penelitian ini akan digunakan sebagai dasar rumusan kajian mengenai sajian pada film "Sang Kiai”.

Unsur sinematik merupakan aspek-aspek teknis dalam produksi sebuah film. Dalam unsur ini peneliti akan lebih membahas dan memaparkan tentang aspek Mise-en-scen dan sinematografi. Mise-en-scen memiliki empat elemen pokok yakni, setting atau latar, tata cahaya, kostum, dan make-up (Himawan, 2008:62). 


\section{Sinematografi}

Sinematografi adalah perlakuan terhadap kamera dan filmnya serta hubungan kamera dengan objek yang diambil (Himawan, 2008:90). Penerapan sinematografi di sebuah film, dibagi menjadi beberapa bagian yang berguna menjelaskan maksud dan tujuan cerita diarahkan pada konteks yang sesuai dengan tema bagian tersebut diantaranya shot, adegan (scene), dan sekuen.

Menurut Askuri Baksin (2009:97), Shot memiliki arti penting sebagai penjelasan bahwa objek dalam film menggambarkan situasi yang nantinya akan berkesinambungan ke dalam cerita berikutnya, shot adalah gambar yang direkam dalam rangkaian scene (adegan). Jadi satu shot merupakan bagian dari scene. Sedangkan adegan adalah satu segmen pendek dari keseluruhan cerita yang memperlihatkan satu aksi berkesinambungan yang diikat oleh ruang, waktu, isi (cerita), tema, karakter, atau motif.

Satu kesatuan dari shot dan adegan yaitu sekuen. Sekuen adalah satu babak besar yang memperlihatkan satu rangkaian peristiwa yang utuh._Satu sekuen umumnya terdiri dari beberapa adegan yang berhubungan. Biasanya film cerita terdiri dari delapan sampai lima belas sekuen (Himawan, 2008:30).

\section{Unsur Naratif}

Naratif adalah suatu rangkaian peristiwa yang berhubungan satu sama lain dan terikat oleh logika sebab-akibat (kaulitas) yang terjadi begitu saja tanpa ada alasan yang jelas. Segala hal yang terjadi pasti disebabkan oleh sesuatu dan terikat satu sam lain oleh hukum kaulitas.

Sebuah film cerita sebuah film cerita sebuah kejadian pasti disebabkan oleh kejadian sebelumnya. Pola pengembangan naratif dalam film umumnya disajikan secara linier dimana sebuah rangkaian peristiwa berjalan sesuai dengan urutan waktu sebenarnya (Himawan, 2008:33).

Penulisan ini tidak semua scene diteliti, yang diteliti adalah scene yang terdapat nilai pendidikan karakter dari perspektif pendidikan. Sedangkan unit analisis yang diteliti oleh penulis disini adalah audio dan visual. Audio meliputi: dialog / monolog serta flashback dan musik. Sedangkan visual meliputi: angel, setting, serta gesture/aksi:

1. Monolog adalah teks yang berupa percakapan tunggal, yaitu berbicara dengan diri sendiri (percakapan batin).

2. Dialog adalah teks yang berupa percakapan lebih dari satu orang.

3. Flashback adalah kilas balik atau menceritakan kembali pengalaman yang sudah dialami.
4. Setting adalah unsur film yang bermuatan tentang konsep, tempat serta properti yang digunakan.

5. Angle adalah pengambilan gambar dari segala sudut.

6. Gesture adalah bahasa tubuh.

\section{Sumber dan Jenis Data}

Adapun sumber data dalam penulisan ini adalah:

a. Data Primer : data yang diperoleh lansung dari objek penulisan yaitu dengan menganalisa terhadap objek penulisan yaitu film "Sang Kiai"

b. Data Sekunder : penulis memperoleh melalui buku dan artikel-artikel yang bersangkutan sesuai dengan fokus penulisan.

\section{Teknik Pengumpulan Data}

Penelitian ini menggunakan teknik pengumpulan data yang sesuai dengan penulisan penelitian ini, yaitu: Dokumentasi yaitu DVD film "Sang Kiai” dengan cara mengidentifikasi adegan-adegan dan dialog-dialog yang mewakili bentuk nilai pendidikan karakter yang muncul berupa audio maupun berupa visual.

\section{PEMBAHASAN}

Penulisan penelitian ini, penulis menggunakan beberapa cara untuk mengumpulkan data-data yang diperlukan. Oleh karena itu, penulis menggunakan teknik pengumpulan data yang sesuai dengan penelitian ini, yaitu: Dokumentasi yaitu DVD film "Sang Kiai" dengan cara mengidentifikasi adegan-adegan dan dialog-dialog yangterdapat nilai pendidikan karakter yang muncul berupa audio maupun berupa visual.

Sebagaimana teori sinematografi yang digunakan dalam penelitian ini dengan mengambil beberapa poin dari adegan film tersebut untuk menentukan pesan-pesan pendidikan terutama pendidikan karakter dalam film "Sang Kiai" tersebut.

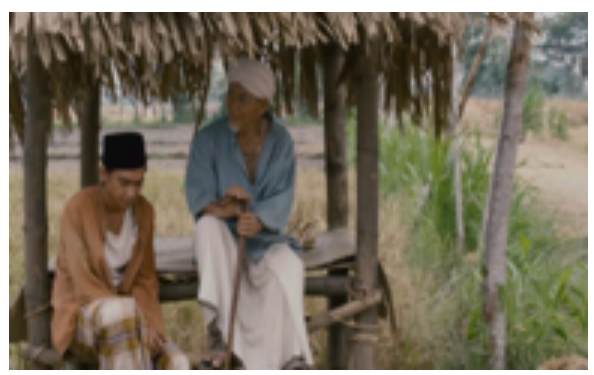

shot : full shot.

Adegan 1 Kyai Hasyim Asyari sedang memberikan tausyiah kepada seorang santrinya di gubug tengah sawah.

Dialog :

Kyai Hasyim: "kita harus bisa mandiri, pesantren tidak boleh membebani biaya pada para santri" 


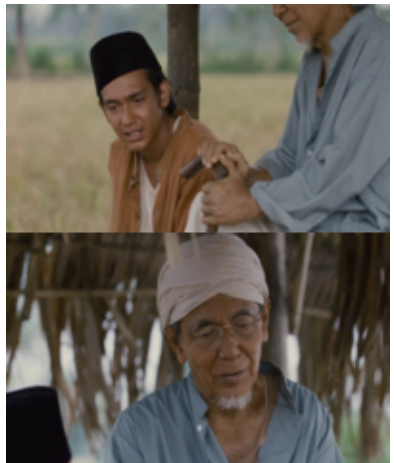

Shot: Medium Close Up ( Pengambilan gambar subjek dari dada hingga ujung kepala yang bertujuan memperlihatkan ekspresi subjek ketika berbicara).

santri : "sekarang saya baru paham kyai kenapa kyai bertani dan berdagang, tapi aaa... kenapa kyai turun tangan sendiri memanen sawah kyai, kyai kan bisa saja menyuruh kula, atau para santri yang lain untuk membantu para petani di sawah

Kyai Hasyim: "dengan membantu para petani, kita bisa merasakan jerih payah mereka. Dengan begitu kita bisa menghargai nasi yang kita makan"

Adegan dan dialog tersebut bila dianalisis mengandung pesan pendidikan dan memiliki nilai pesan pendidikan sosial. Pesan yang disampaikan di kehidupan ini manusia tidak lah hidup sendiri dan tidak lepas bergantung dengan orang lain dan sikap saling menghargai harus ditanamkan kepada siapa saja. Selain itu sebagai pemimpin jangan hanya berdiri di atas tanpa memperhatikan yang di bawah. Seperti Kyai Hasyim Asyari tersebut yang selalu memperhatikan dan peduli kepada para santri dan orang-orang di sekitarnya.

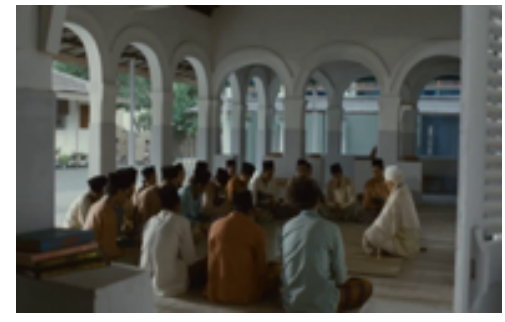

Shot : full shot dikombinasi dengan crabright (gerakan kamera menyamping ke kanan).

Adegan 2 Menit ke 05.11 terdapat kegiatan mengaji kitab yang langsung diajarkan oleh pemeran K.H. Hasyim Asy'ari, kemudian seusai kegiatan mengaji selesai terjadi percakapan antara kyai dengan santri.

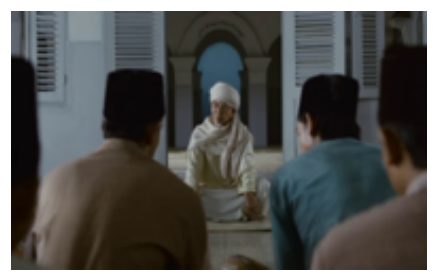

\section{Shot : full shot}

Dialog :

Kyai bertanya kepada Solihin (santri yang mempunyai tugas mencatat pelanggaran, dalam hal ini ketertiban sholat berjamaah) : "Solihin, tadi kamu catat siapa-siapa saja yang tidak ikut sholat berjamaah?"

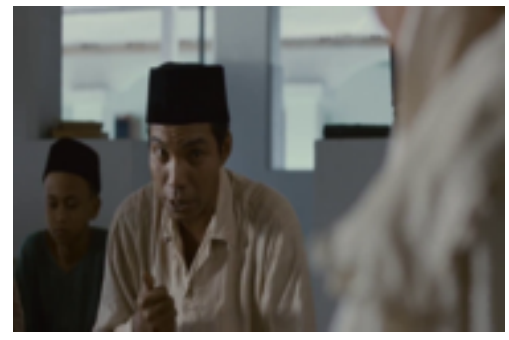

Shot : Over The Shoulder ( pengembilan gambar kamera berada di belakang bahu sebelah kiri kyai dengan memperlihatkan lawan bicaranya).

Dialog :

Solihin : "Khamid yai, biasa...!!! Ketiduran katanya yai."

Kyai : "Apa hukuman bagi santri yang tidak ikut berjamaah?"

Khamid menyanggah : "Kang...!!!, apa iya Cuma saya yang tidak ikut sholat berjamaah?"

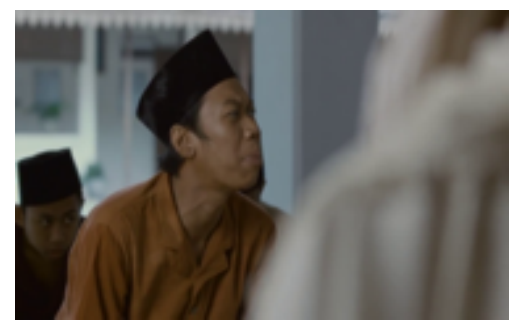

Shot : Over The Shoulder (pengembilan gambar kamera berada di belakang bahu sebelah kiri kyai dengan memperlihatkan ekpresi lawan bicaranya).

Kyai menerima baik sanggahan dari Khamid : "Utarakan saja, siapa lagi yang tidak ikut sholat berjamaah...!!!"

Solihin :"Maaf yai, tadi itu kan harun dan yai ..." Harun menyanggah sebelum Solihin selesai mengutarakan sanggahannya.

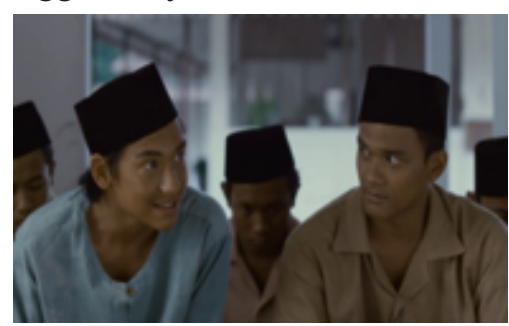

Shot: Two shot ( pengambilan gambar dengan memanfaatkan kedua subjek dengan bertujuan memperlihatkan ekspresi)

"Kang...!!!, saya dan yai itu bareng-bareng petani sholat berjamaah di sawah..." 


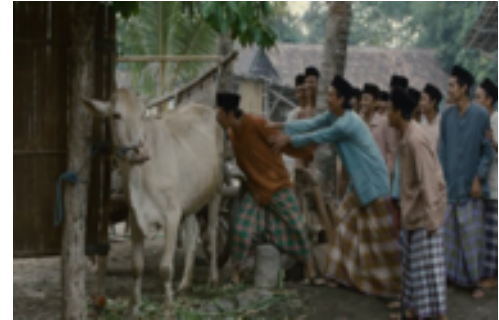

Shot : Full Shot.

Adegan :

Khamid yang melanggar peraturan, tidak ikut berjamaah akhirnya dihukum sebagai konsekwensi atas tindakannya, diantar oleh teman-teman Khamid dihukum mencium pantat sapi yang berada dilingkungan pesantren.

Dialog di atas merupakan tindakan sikap disiplin yang menunjukkan perilaku tertib dan patuh pada berbagai ketentuan dan peraturan. yaitu perilaku yang didasarkan pada upaya menjadikan dirinya sebagai orang yang selalu dapat dipercaya dalam perkataan, tindakan, dan pekerjaan.

\section{SIMPULAN}

Film "Sang Kiai" mampu memberikan nilai pendidikan karakter yang relevan untuk pembentukan karakter. Film "Sang Kiai" menyajikan Audio dan Visual yang banyak memberikan nilai pendidikan karakter melalui adegan mau pun dialog. Film "Sang Kiai" memiliki 9 (delapan) nilai pendidikan karakter yang terkandung di dalam film tersebut diantaranya Religius, disiplin, jujur, kerja keras, demokratis, rasa ingin tahu, semangat kebangsaan, menghargai prestasi, bersahabat/komunikatif yang tercermin pada setiap adegan dalam film "Sang Kiai". Film "Sang Kiai" memberikan satu panutan atau tokoh yang perlu dicontoh yaitu beliau kyai Hasyim Asyari karena memberikan suri tauladan yang baik sebagai pemimpin.

Film tersebut sangat dianjurkan untuk ditonton untuk para generasi muda sekarang. Karena banyak terjadinya kriminalitas seperti korupsi, pembunuhan, penipuan, dan kejahatan yang lain film ini bisa dijadikan sebagai media komunikasi kepada masyarakat agar pendidikan karakter sejak dini itu sangat diperlukan.

\section{SARAN}

Peneliti lain yang akan melakukan penelitian sejenis hendaknya memiliki ruang lingkup kajian yang berbeda. Selain itu, peneliti lain hendaknya menggunakan media pembelajaran yang berbeda sehingga data yang diperoleh lebih beragam.

Siswa hendaknya memahami nilai-nilai pendidikan karakter, sehingga siswa dapat menanamkan dan melaksanakan dalam kehidupan sehari-hari dengan lebih berprilaku positif., baik di lingkungan sekolah maupun di lingkungan masyarakat.

Guru hendaknya dapat mengadakan pembelajaran di sekolah dengan lebih variatif yaitu dapat menggunakan media pembelajaran audio, visual, maupun audiovisual lainnya untuk memberikan pemahaman kepada siswa cara berprilaku yang baik sesuai dengan pendidikan karakter dalam kehidupan sehari-hari. Selain itu, guru hendaknya dapat membekali siswa dalam pembentukkan karakter agar terbentuk perilaku siswa yang terpuji.

Kepala sekolah hendaknya memberikan contoh dalam berperilaku yang baik dengan tindakan serta hubungan antar guru dan siswa. Selain itu kepala sekolah hendaknya memberi contoh dan menjadi tauladan dalam memprakttekkan setiap nila-nilai pendidikan karakter dalam pendidikan sehari-hari, sehingga akan tercipta iklim yang kondusif bagi pembentukkan karakter siswa.

\section{DAFTAR RUJUKAN}

Baksin, Askurifai. Videografi Operasi Kamera \& Teknik Pengambilan gambar. Bandung: Penerbit Widya Pedjadjaran.2009.

Departemen Pendidikan Nasional.2008. Kamus Besar Bahasa Indonesia. Jakarta: Balai Pustaka.

Gunawan, Heri. Pendidikan Karakter Konsep Dan Implementasi. Bandung: Alfabeta. 2012

Hasbullah.2001, Dasar-Dasar Ilmu Pendidikan.Jakarta: PT. Raja Grafindo Persada.

Hadari Nawawi. 1995. Metode Penelitian Bidang Sosial. Yogyakarta: UGM.

Haryono, Timbul. Seni Pertunjukkan Seni Rupa Dalam Prespektif Arkeologi Seni. (Surakarta. ISI Press Solo) 2008 .

Kusnadi, Wawan. 1996. Komunikasi Massa:Sebuah Analisis Media Televisi. Jakarta: Rineka Cipta.

Littlejohn, S.W., dan Foss, K.A. 2005. Teori Komunikasi Edisi 9. Jakarta: Salemba Humanika.

McQuail, Dennis. 1987. Teori Komunikasi Massa Suatu Pengantar. Edisi Kedua. Terjemahan oleh Agus Dharma \& Aminuddin Ram. 1994. Jakarta: Erlangga. Miles, Mattehhew B. Analisis Data Kualitatif. Jakarta : PUI.2007

Mulyana, Deddy. 2007. Ilmu Komunikasi: Suatu Pengantar. Bandung: PT Remaja Rosdakarya. 
Mulyana, Deddy. 2005. Ilmu Komunikasi Suatu Pengantar. Bandung: Remaja Rosdakarya.

Nurdin, Masfil. Don Livingston Film And The Director, Jakarta. Yayasan Artis Film.1969/1980.

Pratista, Himawan. Memahami Film. Yogyakarta: Homerian Pustaka. 2008

Prastowo, Andi. Metode Penelitian Kualitatif dalam Perspektif Rancangan Penelitian. Yogyakarta: Ar-Ruzz Media.2012.

Sani, Asrul. Cara Menilai Sebuah Film. Jakarta: Yayasan Citra.1992.

Soleh, M. (2005). Politik pendidikan:Membangun sumber daya bangsa dengan peningkatan kualitas pendidikan. Jakarta: Institute for Public Education (IPE), Penerbit Grafindo Khazanah Ilmu.

Soleh, M. (2007). Cita-cita realita pendidikan: pemiiran dan aksi pendidikan di Indonesia. Jakarta: Institute for Public Education (IPE).

Sumordjo, Jakob. Estetika Paradoks. Bandung: Sunan Ambu Press.2006.

Sumarno, Marselli. Dasar-dasar Apresiasi Film. Jakarta: PT Grasindo. 1996.

Sugiyono. Memahami Penelitian Kualitatif. Bandung: CV Alfabeta. 2013

Wibowo, Fred. Dasar-dasar Produksi Program Televisi. Jakarta: Grasindo.1997.

Depdikbud.1993. Kamus Besar Bahasa Indonesia. Jakarta: Balai Pustaka.

Lexy J. Moleong. 1988. Metode Penelitian Kualitatif. Bandung: PT. Remaja.

Patton M.C. 2009. Metode Evaluasi Kualitatif. Jogjakarta: Pustaka Pelajar.

Soedarsono.1990. Metodologi Penelitian Seni Pertunjukan dan Seni Rupa. Bandung: MSPI.

http://filmsangkiai.com/

https://griyawardani.wordpress.com/2011/05/19/ nilai-nilai-pendidikan/ 